\title{
PILOMATRIXOMA
}

\section{(Calcifying Epithelioma of Malherbe)}

Haroon M. Qazi, M.D. F.A.C.S., Plastic Reconstructive Surgery of the Hand, and

Randall W. Strate, M.D., Department of Pathology, Methodist Hospital of Indiana

The pilomatrixoma is a benign skin lcsion bearing initially resemblance to an inclusion cyst. Later the tumor enlarges and may assume the form of a large cyst ${ }^{2}$ or an ulcerated tumor resembling basoquamous cell carcinoma. (Figure I and Figure 20).

Pilomatrixoma (calcifying epithelioma of Malherbe) was described initially by Malherbe and Chenatasis' in 1880. Its similarity to the more common cysts and its confusing cell origin have contributed to its clinical obscurity. Forbis and Helwig ${ }^{3}$ suggested in 1961, renaming this lesion as pilomatrixoma (stemming from primitive hair matrix cells).

Incidence: Several authors ss report the incidence as one in 2000 surgical specimens, whereas ${ }^{h}$ anolher study reports an incidence of one per 824 specimens.

The tumor is seen in all age groups, but $40 \%$ are seen before age 10 and $60 \%$ before age 20 . A female 10 male ratio of $3: 2$ is reported, with the white race primarily alfected.

Differential diagnosis of ten includes sebaceous cysts, giane cel] tumor, ossifying hematoma. metastatic calcification. chondroma, dermoid cysts, foreign bod reaction and degenerating fibroxanthoma. The tumor almost always occurs singly. The arms (35\%), the face (21\%), the neck (13\%), and the thighs (10\%) were the most common sites in the patients studied by Forbis and Helwig.

Radiologic Appearance: Because the tumor is generally small and innocuous, radiologic examination is rarely performed, however, the radiographic appearance of heavily calcified tumors is distinceive. The tumors have a regular contour and are sharply demarcated from the surrounding fat. The overlying skin may be normal but usually is thin. Calcification' may not be visible with conventional soft tissue technique, and low-kilovoltage radiography with nonscreen or industrial film is preferable. Most reported cases have homogeneous speckles or sandlike calcification. However, large dense foci of calcjfication have been described.

The radiographic finding of a solitary, sharply demarcated subcutaneous tumor with extensive sandlike dense local calcification is probably pathognomonic of pilomatrixoma. However, the differential diagnosis mentioned above should be kept in mind as hemangiomas may contain small calcification but sand-like or dense calcification does not occur. Soft tissue osteosarcoma and ossifying fibromas may be confused radiologically with pilomatrixoma.

Pathological Description: Grossly, the lesions are round or oval circumscribed masses, situated as a rule in the dermis. but sometimes in the subcutancous tissue, on cut section. These tumors are gray, white or brown with yellow streaks. Their consistency varies from soft to friable. firm and even stony hard. They are rarely cystic in contrast to the epidermal cysts.

Microscopically the tumor is surrounded by compressed collagen. It is composed of sheets and bands of epithelial cells, often folded or convoluted and separated by connective tissues. (Figure 3) Occasionally smaller masses of epithelial cells arranged in a circular configuration were observed at the periphery of larger masses. The basic cell of pilomatrixoma is small and basophilic, with scant. pale eosinophilic cytoplasm, a snall nucleous. finely divided nuclear chromatin and no visible cellular boundary. These cells occur in solid masses and numerous mitoses can be seen. The transition from basophilic cells to shadow cells extends over an area of 6 to 8 cclls. The nucleous gradually is reduced to an eosinophilic pyknotic mass. The size of the shadow cells remain the same as the parent basophilic cell. Occasionally transition to squamoid cells with keratin and parakeratin has been described.

Calcification occurs early, apparently as dusting of the hasophilic material throughout the shadow cells or solid purple. amorphous nuass. As a rule it is noted in the center of the shadow group.

Case Report: More than 1500 cases have been reported in the literature and we report another case treated recently at Methodist Hospital. Indianapolis. Indiana.

An 84 year old Negro female, a poor historian, was seen on November 17. 1978 with a history of having a mass on the right side of the lace for the last few years. (Figure 1 and Figure 2) The exact duration was unknown. Patient was hypertensive and had a mild stroke in the past but had not been seeing any 
physician regularly. The patient's sister indicated that the mass had ulcerated and became indurated and hence she brought her to the hospital. General system review indicated a nodular goitre, hypertension and calcified fibroid uterus on $\mathrm{x}$-ray. The mass was $3 \mathrm{~cm}$. in diameter over the right zygomaticotemporal area, ulcerated, indurated and adherent to the deep tissue. No regional lymphadenopathy was present. Clinical impression was a basal cell carcinoma. A wide excision of the tumor under frozen section control and loop magnilication was done to preserve branches of the facial nerve. The final histopathological examination was pilomatrixoma. calcifying epithelioma of the Malherbe.

The patient's post operative course was uncventful. There is no evidence of recurrence.

Discussion: According to Forbis and Helwig ${ }^{3}$ pilomatrixoma arises from primitive cells that normally differentiate towards hair matrix cells. The end product of imperfect differentiation are hyalinized shadow cells (which are histochemically similar to inner root sheath keratin), squamoid cells and amorphous debris. The tumor consists of sheets and bands of primitive epithelial cells (basophilic cells) in a connective tissue stroma. Shadow cells generally occur within nests of basophilic cells and a zone of transition is often evident. Calcification was present in $84 \%$ of 240 tumors studied by Forbis and Helwig.

These tumors are unequivocally benign though clinically may assume a very large size and invade local tissue as in the case reported by Rothman and Kendall' or show superficial ulceration mimicking basal or squamous cell carcinoma. The pronounced mitotic activity of the basophilic cells ted to the erroneous initial diagnosis of squamous or basal cell carcinoma in $8 \%$ of the patients in some series.

Our case emphasizes the locally aggressive potential of a commonly benign lesion that is diagnosed correctly only by a pathologist after excision.

\section{REFERENCES}

1. Malherbe, A. and Chenantasis, 1.: Nolc sur Iepithelioma calcifie des glandes sebasees. Prog. Mcd. Paris, 8:826-828. (Ocl. I6. 1880).

2. Rothman and Kendall.: Arch. Surg.. 111: 80-87. 1976.

3. Forbis, R., Ir. and Helwig. E.B.: Pilomartrixoma (Calcifying epithelioma). Arch. Derm.. 83: 606-618. 1961.

4. Ch in. K.Y.: Calciticd Epitheliona of the Skin. Am. J. Path.. 9: 497-524. (July) 1933.

5. Lever, W.F. and Griesemer. R.: Calcilying epithelioma of Malherbe. Arch. Derm., 59: 506, 1949.

6. Kethley. L. Joe et al.: Pilomatrixoma (Calicifying epithelioma of Malherbe.) J. Oral Surg., 36: 618-620. (AugusI) 1978.

7. Haller. Jack O. ef al.: Pilomatrixoma (Calcifying Epitheliona of Malherbe). Radiographic Fealures. Radiology. 123: 151153. 1977.

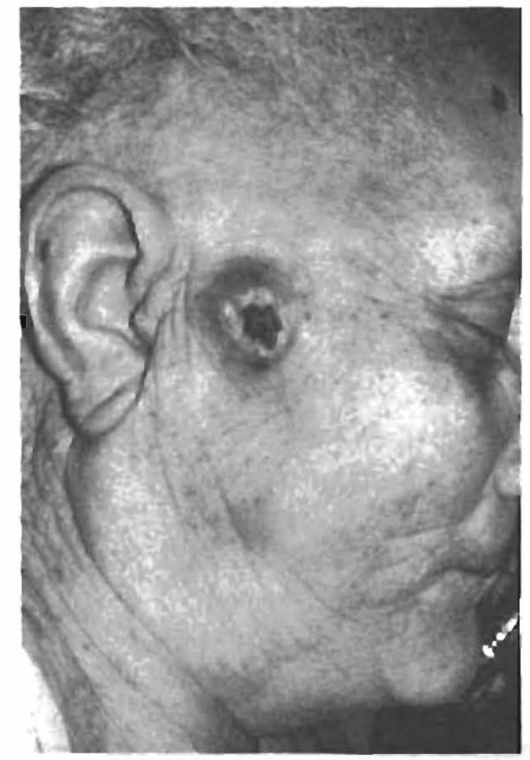

FIGURE: I - Hre-Uperanve Pilomarrixoma Resembling Basosquamous Cell Carcinoma

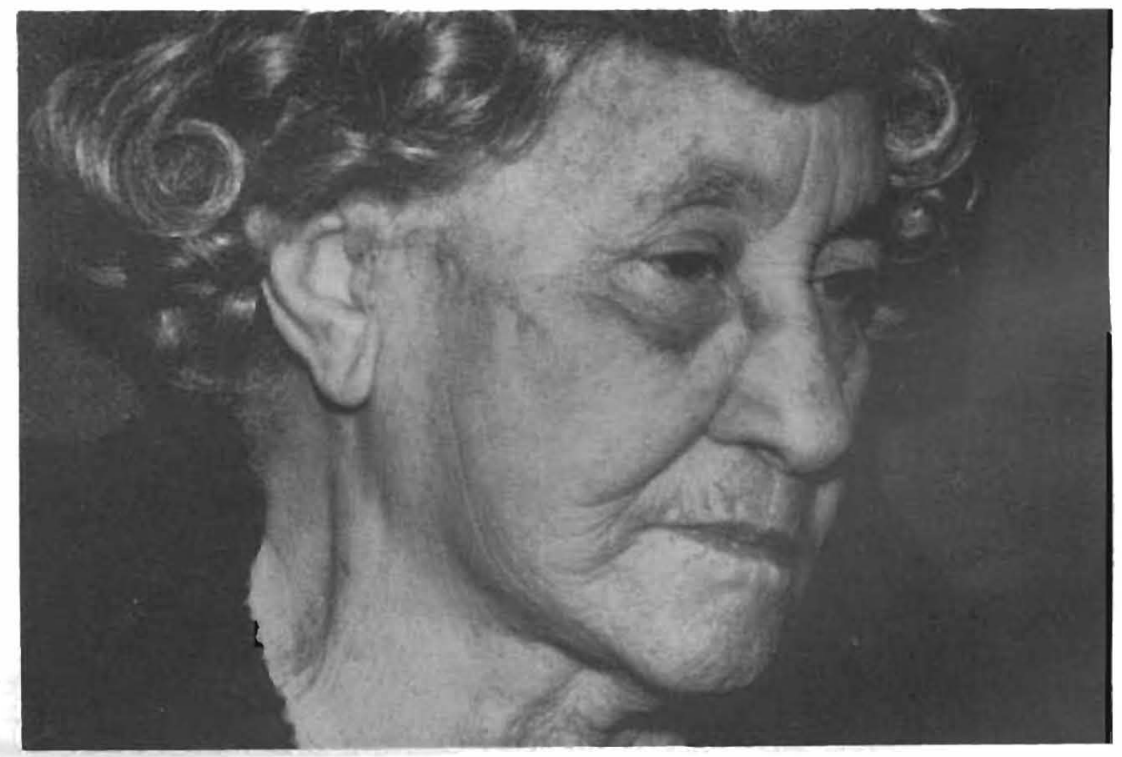

FIGURE: 2 - Post-Operative 3 Wks. Excision Pilomatrixoma 


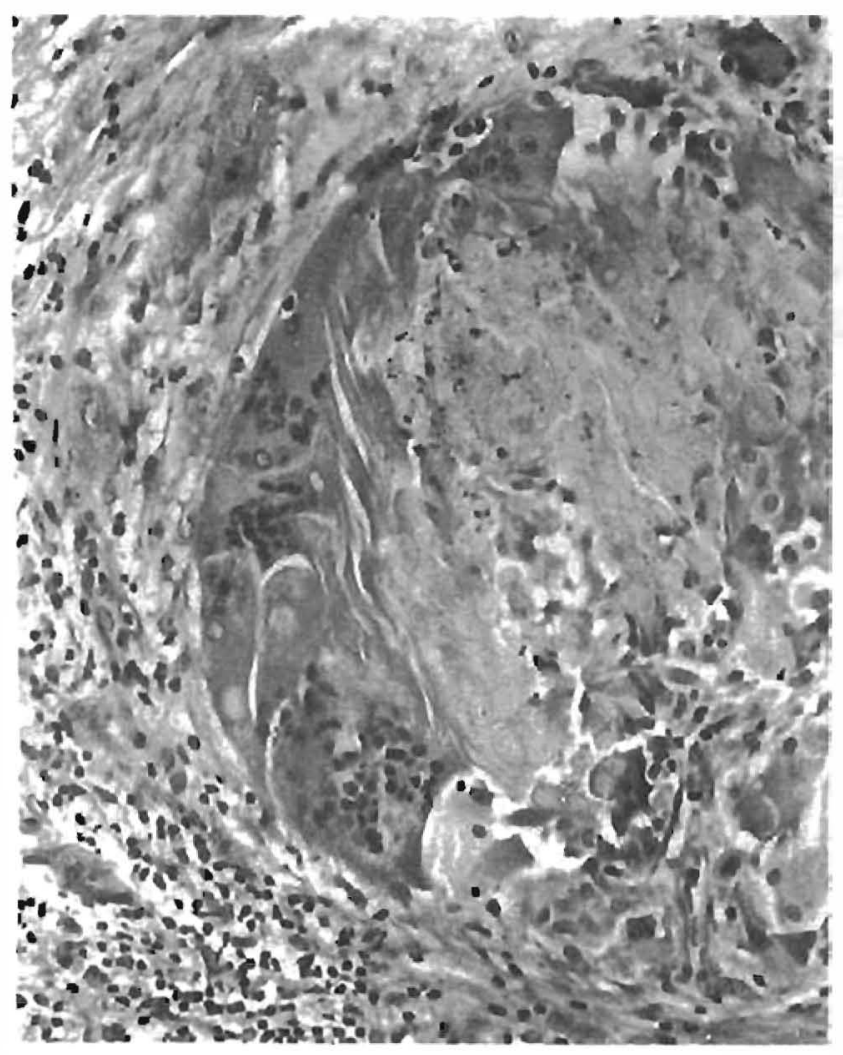

FIGURE: 3 - Focus of foreign body reaction, chronic inflammation and calcification in pilomatrixoma

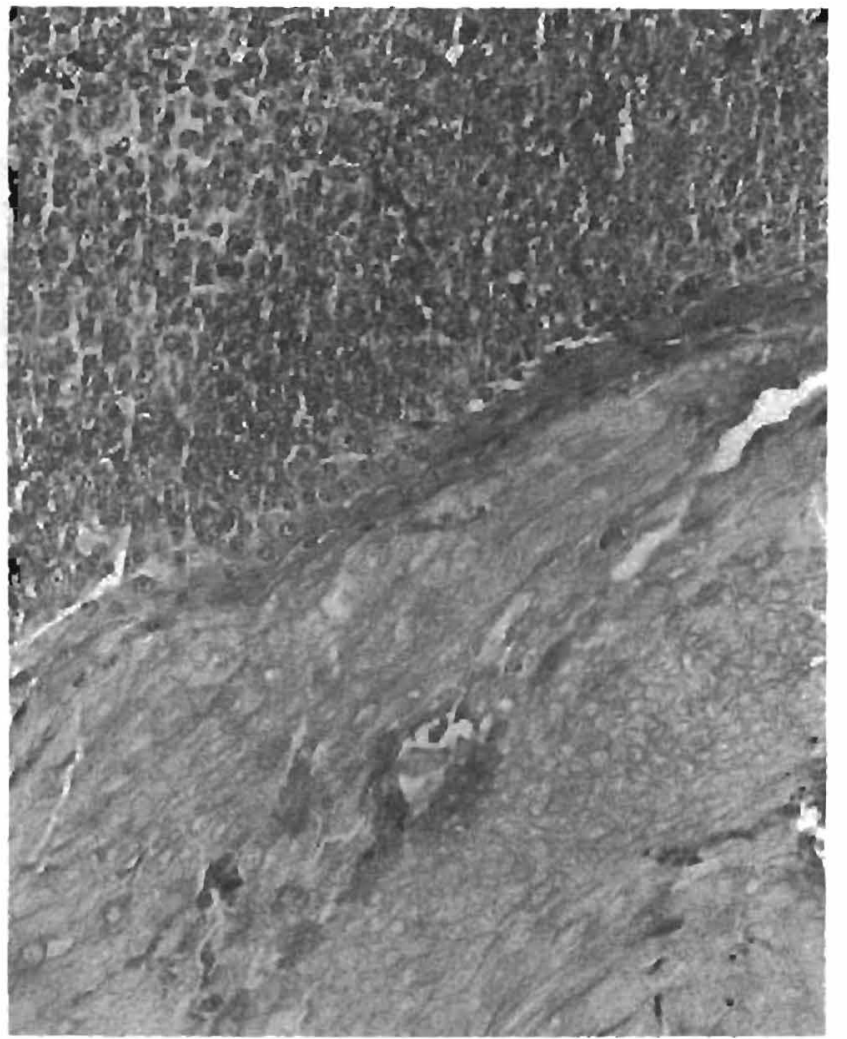

FIGURE: 4 - Medium power view of classic basophil cells merging into so-called "ghost cells" 